IZA DP No. 7388

Who Moves and For How Long:

Determinants of Different Forms of Migration

Daniela Borodak

Matloob Piracha

May 2013 


\title{
Who Moves and For How Long: Determinants of Different Forms of Migration
}

\author{
Daniela Borodak \\ France Business School \\ and CERDI, Clermont-Ferrand \\ Matloob Piracha \\ University of Kent \\ and IZA
}
Discussion Paper No. 7388
May 2013

IZA
P.O. Box 7240
53072 Bonn
Germany

\author{
Phone: +49-228-3894-0 \\ Fax: +49-228-3894-180 \\ E-mail: iza@iza.org
}

\begin{abstract}
Any opinions expressed here are those of the author(s) and not those of IZA. Research published in this series may include views on policy, but the institute itself takes no institutional policy positions. The IZA research network is committed to the IZA Guiding Principles of Research Integrity.

The Institute for the Study of Labor (IZA) in Bonn is a local and virtual international research center and a place of communication between science, politics and business. IZA is an independent nonprofit organization supported by Deutsche Post Foundation. The center is associated with the University of Bonn and offers a stimulating research environment through its international network, workshops and conferences, data service, project support, research visits and doctoral program. IZA engages in (i) original and internationally competitive research in all fields of labor economics, (ii) development of policy concepts, and (iii) dissemination of research results and concepts to the interested public.
\end{abstract}

IZA Discussion Papers often represent preliminary work and are circulated to encourage discussion. Citation of such a paper should account for its provisional character. A revised version may be available directly from the author. 
IZA Discussion Paper No. 7388

May 2013

\section{ABSTRACT \\ Who Moves and For How Long: Determinants of Different Forms of Migration}

This paper analyses the determinants and correlates of different forms of migration, including circular, temporary and permanent. Using Moldovan data we show that age, education, number of children in a household and social as well as economic development in the region of origin play a crucial role in the decision to migrate permanently or on temporary/circular basis. We believe that understanding who moves and whether temporarily or circularly will help formulate more effective migration policies both in the sending and receiving countries.

JEL Classification: $\quad$ C35, F22, J61

Keywords: circular migration, return migration, nested logit, Moldova

Corresponding author:

Matloob Piracha

School of Economics

Keynes College

University of Kent

Canterbury, Kent CT2 7NP

United Kingdom

E-mail: M.E.Piracha@kent.ac.uk 


\section{Introduction}

Despite a significant increase in temporary migration over the past two decades, only scant attention has been paid to this form of labour movement. Since all forms of migration affect not only the migrant and their families, but both source and host countries as well, it is important to understand the determinants of each type of movement, from permanent to temporary to circular. This paper adds to the nascent literature on this topic by using Moldovan data.

Although temporary migration, based on bilateral agreements between number of home and host (notably Germany) countries has been in existence since 1960s, the different forms of migration were not so prevalent until 1990s. For instance, in 2006 alone nearly 2.5 million individuals were admitted into the OECD countries on temporary contracts, which is over three times the number of legally admitted permanent migrants (OECD 2008). The advent of relatively liberalised regimes in ex-Soviet republics resulted in a spurt of temporary and circular migration in Europe. Two of the main senders of these forms of migrants are Albania (to Greece and Italy) and Moldova (mainly to Russia but to some other Commonwealth of Independent States plus the EU as well). However, there is limited analysis of this form of migration. A few exceptions are Constant and Zimmermann (2011), Constant and Zimmermann (2012) and Vadean and Piracha (2010). ${ }^{1}$

Constant and Zimmermann used the German Socioeconomic Panel data in both papers and showed that more than 60 percent of those who entered Germany on a guest-worker permit exited and re-entered the country at least once between 1984 and 1994. However, their analysis is from the receiving country perspective and it is also not clear if in their case all repeat migrants went back to the home country or went to a third country to try their luck before returning to Germany. Vadean and Piracha (2010) analyse the determinants of temporary and circular migration from the source country perspective. Using data from Albania, a country where 30 percent of the population is a migrant at any given time with big proportions of the migrants moving back and forth from Albania to primarily Greece, they show that legal status in the host country and the family structure are key elements in determining whether migration is long term or not while savings target and education level

\footnotetext{
${ }^{1}$ For a more detailed survey of the related literature see Constant and Zimmermann (2013).
} 
plays an important role in the decision to return permanently to the home country after one migration episode.

This paper extends Vadean and Piracha (2010) by analysing the determinants that affect the decision to migrate repeatedly (circularly), only once for a short term with a permanent return to the home country (temporarily) or permanently, using Moldovan survey data. Like Albania, Moldova is a country of mass migration with a large proportion of the population (more than 20 percent) involved in different forms of migration at any given time. However, there are a number of differences as well. Not only is Moldova part of the Commonwealth of Independent States (CIS), and hence enjoys visa free travel to other CIS countries, which includes Russia, but a large number of Moldovans have dual citizenship (Moldvoa and Russia) as well. This makes moving to another country easier and hence cheaper, which might encourage revolving door or va-et-vient type of movement more than other forms of migration. Hence we expect the determinants of different forms of migration from Moldova to differ from those where visa regimes are much tighter, e.g., Turkish migration to Germany or Albanians to Greece.

Rest of the paper is organised as follows. Analytical framework is briefly presented in Section 2 while data is explained is Section 3. Sections 4 and 5 present the empirical methodology and results, respectively. Last section concludes the paper.

\section{Analytical Framework}

There are at least two ways in which migration decision process could be analysed. One is in which the form of migration is decided at the initial stage. In other words, the migrant decides at the start of the process how long to migrate for and whether to permanently return or not (see the decision tree in Fig 1). Given higher income opportunities abroad and

preference for living at home, individual utility is assumed to depend on a time path of residence in the home and host country and is maximised by choosing the optimal amount of time spent abroad as well as the frequency of trips. 
Figure 1: Return and re-migration integral to the initial migration decision

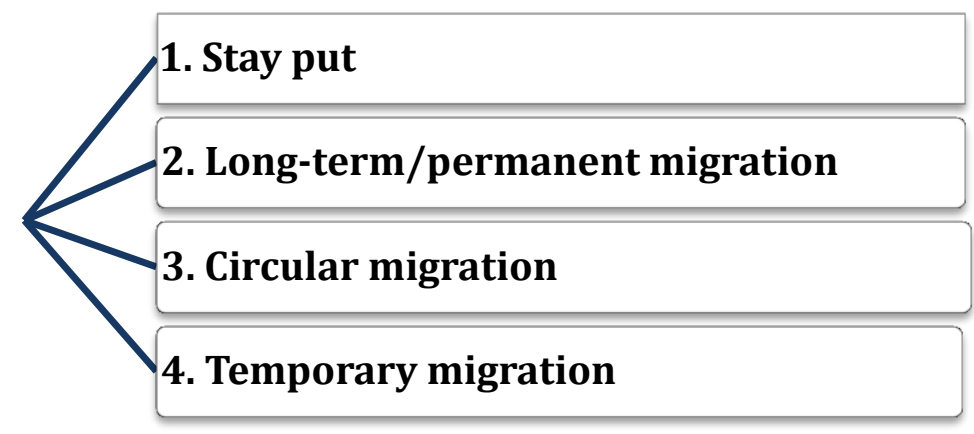

However, it has been argued that the migration decision process is endogenous in nature and that the migrant, who is faced with uncertainty and imperfect information at the start of the process, basis the decision to stay in the host country or return to the home country once the migrant has achieved the first stage, i.e., once he is abroad (see Galor and Start 1990; Dustmann 1997; Piracha and Zhu, 2012). In this setup, a migrant decides while abroad, based on the realities he faces, whether he should return to the home country or not. Once back home, there is another layer in the decision process regarding re-migration, perhaps due to problems of re-integration, the failure to find a suitable job or having to acquire more capital for the business started after return. In this case, the decision process would have the form presented in Fig 2. This decision process is intuitively more appealing; therefore in the empirical analysis we will focus on this structure.

Figure 2: Multiple revisions of the migration decision: Three-Level Nest Structure for Four Alternatives

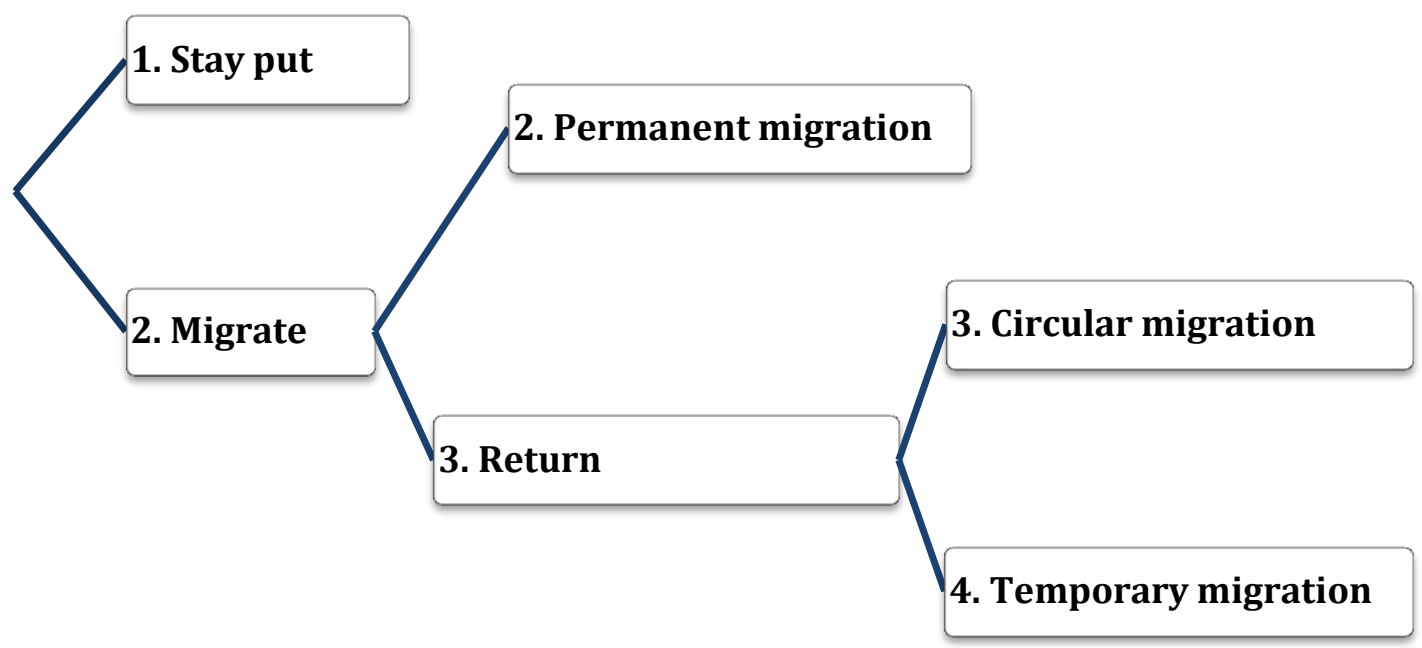




\section{Data}

The data, collected by the CBSAXA in July and August 2006, is a representative survey of 3940 households, which generated a total sample of 14,068 people including 4,481 (31.85 percent) with migration experience abroad. A screening selection for valid answers on migration led us to a final sample of 9,925 individuals, aged between 16 and 65, and includes four sub-samples: 6,833 non-migrants, 2,380 long term/permanent migrants, 412 temporary migrants (i.e. individuals who migrated only once and were back in Moldova at the time of the survey) and 300 circular migrants (i.e. individuals who migrated more than once in the past and were back in Moldova at the time survey was conducted). Table 1 shows the summary statistics of our variables for the four sub-samples, sorted by the variable categories including individual and household characteristics, poverty perception variables, legal status, network variables and community variables.

Circular migrants are younger than non-migrants but older than permanent migrants. They are more frequently women compared with temporary migrants, but women are more likely to become permanent migrants. Circular migrants are more educated than those who migrate temporarily and they also more frequently have legal migration status than the temporary migrants. In addition, circular migrants come from regions with significantly higher social and economic development indexes compared to other forms of migrants. However, non-migrants are more frequently from regions with better infrastructure and other relevant indexes.

\section{Empirical Model}

We consider the case where an individual has four available alternatives: no migration or stay (ST), permanent migration (PM), circular migration $(\mathrm{CM})$, and temporary migration (TM). We use the three-level nested logit to estimate the decision process described in Fig 2. The derivation of the nested logit model is based on the assumption that some of the alternatives share common components in their random error terms. That is, the random term of the nested alternatives can be decomposed into a portion associated with each alternative and a portion associated with groups of alternatives.

In the model depicted by the three-level nesting structure in Fig 2, the lower level nest is a binary choice between circular and temporary migration, conditional on choice of return (R); the second level nest represents a choice between permanent migration and return; and the 
highest level represents a choice between no migration and migration. The utility equations for these alternatives are:

- no migration

$$
\mathrm{U}_{\mathrm{NM}}=V_{N M}+\varepsilon_{N M}
$$

- permanent migration $\mathrm{U}_{\mathrm{PM}}=V_{M}+V_{P M}+\varepsilon_{M}+\varepsilon_{P M}$

- circular migration $\mathrm{U}_{\mathrm{CM}}=V_{M}+V_{R}+V_{C M}+\varepsilon_{M}+\varepsilon_{R}+\varepsilon_{C M}$

- temporary migration $\mathrm{U}_{\mathrm{TM}}=V_{M}+V_{R}+V_{T M}+\varepsilon_{M}+\varepsilon_{R}+\varepsilon_{T M}$

The utility terms for permanent, circular and temporary migration each include a distinct observed component, $V_{P M}, V_{C M}, V_{T M}$, and a common observed component, $V_{M}$, for migration choice (M). They also include distinct random components, $\varepsilon_{P M}, \varepsilon_{C M}, \varepsilon_{T M}$, and a common random component, $\varepsilon_{M}$. The utility terms for each circular and temporary migration includes a common observed component, $V_{R}$, for return $(\mathrm{M})$ and a common random component, $\varepsilon_{R}$. The common error component creates a covariance between the total errors for permanent migration, $\varepsilon_{M}+\varepsilon_{P M}$, for circular migration $\varepsilon_{M}+\varepsilon_{R}+\varepsilon_{C M}$ and for temporary migration, $\varepsilon_{M}+\varepsilon_{R}+\varepsilon_{T M}$. This covariance violates the assumption underlying the multinomial logit (MNL) model representing an increased similarity between pairs of nested alternatives (circular and temporary migration, in this case) and leads to greater cross-elasticity between these alternatives.

The total error for each of the four alternatives is assumed to be distributed Gumbel with scale parameter equal to one. The distinct error components, $\varepsilon_{P M}, \varepsilon_{C M}, \varepsilon_{T M}$, are also assumed to be distributed Gumbel, but with scale parameters, $\mu_{M}$ and $\mu_{R}$, bounded by one and positive infinity. We estimate $\theta_{M}=\frac{1}{\mu_{M}}$ and $\theta_{R}=\frac{1}{\mu_{R}}$, the inverse of the Gumbel scale parameters.

The logsum parameter at each level is restricted to be between zero and the logsum parameter at the next higher level of the nesting structure: $0<\theta_{M}<1$ and $0<\theta_{R}<\theta_{M}$. The probabilities for each nested alternative in the lowest level, circular and temporary migration, conditional on choice of return $(\mathrm{R})$ are given by: 


$$
\begin{aligned}
& \operatorname{Pr}(T M \mid R)=\frac{\exp \left(\frac{V_{T M}}{\theta_{R}}\right)}{\exp \left(\frac{V_{T M}}{\theta_{R}}\right)+\exp \left(\frac{V_{C M}}{\theta_{R}}\right)} \\
& \operatorname{Pr}(C M \mid R)=\frac{\exp \left(\frac{V_{C M}}{\theta_{R}}\right)}{\exp \left(\frac{V_{T M}}{\theta_{R}}\right)+\exp \left(\frac{V_{C M}}{\theta_{R}}\right)}
\end{aligned}
$$

where $\theta_{R}$ is the logsum parameter at the lowest (i.e., return) nest level.

The probabilities for each alternative in the second level nest, permanent migration and return, conditional on the choice of migration $(\mathrm{M})$ modes are:

$$
\begin{gathered}
\operatorname{Pr}(P M \mid M)=\frac{\exp \left(\frac{V_{P M}}{\theta_{M}}\right)}{\exp \left(\frac{V_{P M}}{\theta_{M}}\right)+\exp \left(\frac{V_{R}+\theta_{R} \Gamma_{R}}{\theta_{M}}\right)} \\
\operatorname{Pr}(R \mid M)=\frac{\exp \left(\frac{V_{R}+\theta_{R} \Gamma_{R}}{\theta_{M}}\right)}{\exp \left(\frac{V_{P M}}{\theta_{M}}\right)+\exp \left(\frac{V_{R}+\theta_{R} \Gamma_{R}}{\theta_{M}}\right)}
\end{gathered}
$$

where $\theta_{M}$ is the logsum parameter for the intermediate level (i.e., for migration) and $\Gamma_{R}$ is the "logsum" of the exponents of the nested utilities for the lower nest level:

$$
\Gamma_{R}=\log \left[\exp \left(\frac{V_{T M}}{\theta_{R}}\right)+\exp \left(\frac{V_{C M}}{\theta_{R}}\right)\right]
$$

Finally, the probabilities for "no migration" and "migration" nest are:

$$
\begin{aligned}
& \operatorname{Pr}(N M)=\frac{\exp \left(V_{N M}\right)}{\exp \left(V_{N M}\right)+\exp \left(V_{M}+\theta_{M} \Gamma_{M}\right)} \\
& \operatorname{Pr}(M)=\frac{\exp \left(V_{M}+\theta_{M} \Gamma_{M}\right)}{\exp \left(V_{N M}\right)+\exp \left(V_{M}+\theta_{M} \Gamma_{M}\right)}
\end{aligned}
$$


where $\theta_{M}$ is the logsum parameter for the intermediate level, and $\Gamma_{M}$ is the logsum of the exponents of the nested utilities for the intermediate nest:

$$
\Gamma_{M}=\log \left[\exp \left(\frac{V_{P M}}{\theta_{M}}\right)+\exp \left(\frac{V_{R}+\theta_{R} \Gamma_{R}}{\theta_{M}}\right)\right]
$$

The marginal probabilities of permanent, temporary and circular migration are the product of the probabilities of each branch from the root (top of the tree) to the alternative:

$$
\begin{aligned}
& \operatorname{Pr}(P M)=\operatorname{Pr}(P M \mid M) \times \operatorname{Pr}(M) \\
& \operatorname{Pr}(T M)=\operatorname{Pr}(T M \mid R) \times \operatorname{Pr}(R \mid M) \times \operatorname{Pr}(M) \\
& \operatorname{Pr}(C M)=\operatorname{Pr}(C M \mid R) \times \operatorname{Pr}(R \mid M) \times \operatorname{Pr}(M)
\end{aligned}
$$

\section{Empirical Results}

Table 2 presents the results from the estimation of the three-level nested logit model (NLM). The decision to migrate is modelled in the first stage of the decision tree in Fig $2 .^{2}$ The results from the migration equation show that the likelihood of migration, compared to not migrating, is lower for females, persons with relatively higher educational level, persons from wealthier households and those from regions with higher economic and social development indexes. It is also lower for those who do not have double Moldovan-Russian citizenship, which can be easily interpreted as the cost of migration is lower for those who have dual citizenship as it makes migration a relatively easier venture.

The decision to migrate temporarily, conditional on migration, is modelled in the second level of the decision tree, where the choice variable is return (temporary and circular migration) versus permanent migration. As predicted by various migration models and confirmed by empirical findings, permanent migration should be a decision taken at a younger age as social and financial relocation costs are lower and the larger time span until the end of the active lifetime allows for higher gains (see, for instance, Radu and Epstein, 2007). However, if migrated at a younger age then as more time is spent in the host country, the

\footnotetext{
${ }^{2}$ For the sake of completeness we ran estimations for the decision tree in Fig 1 as well, using multinomial logit model of the choice of migration. The Hausman test rejects the assumption of IIA, which means that the MLE does not to capture our data correctly. Results of MLE are available upon request. Furthermore, LR test for IIA implies that there is correlation in the unobserved characteristics of the grouped modes. This indicates that a nested logit model is more appropriate in this case than a standard MLE model. This is coherent with our results of the Hausman test for IIA in the multinomial logit.
} 
possibility of return to the host country should be lower. Furthermore, having obtained legal residence should give migrants access to legal and better employment and, thus, increase the probability of staying abroad permanently.

Our results are consistent with findings in the literature -- they show that age and an illegal migration status in the host country are negatively and significantly related to the probability of return. In addition, the probability of return increases if the migrant is married, has another household member abroad but decreases with the proportion of children in the household. The last aspect perhaps exerts more financial pressure which affects the decision to earn more in the host country and therefore stay for a much longer time period.

The third level of choice modelled is between circular and temporary migration. The probability to migrate temporarily (conditional on migration followed by permanent return), increases with age, the proportion of children, education level and the economic development of the origin region. On the other hand, an individual is more likely to be a circular migrant if there is a strong community network (high social development index) in the home country as that makes re-assimilation upon return much easier. In addition, lower the perception of poverty in 1998, lower are the chances for an individual to be a circular migrant rather than a temporary one. One possible explanation of that result is that Moldovans are perhaps better at diversifying risk across the family members and as some members keep on working in the home country, either in farm or non-farm occupations, the joint family income is overall higher for those who migrate repeatedly.

Table 3 presents the estimated probabilities for the NLM. The estimated probabilities for each nested alternative in the lowest level, the probabilities for each alternative in the second level nest, the probabilities for "no migration" and "migration" nest, and the marginal probabilities of permanent, temporary and circular migration. The average predicted probabilities estimated with the nested logit model no longer equal the sample probabilities, but they are quite close. Also, we can see from the last rows that conditional on migrating, there is a 68 percent probability that the person has moved on permanent basis. One interpretation of this result could be that individuals decide to stay for longer in the destination country either because they couldn't reach their target savings or perhaps there is no job prospects back in Moldova. If the person decides to return, then he has a 56 percent chance to be a temporary migrant, and only 44 percent to be a circular migrant. 


\section{Conclusions}

The main objective of the paper was to study the correlates and determinants of different forms of migration from Moldova, a country with a high level of, mostly temporary or circular, out migration. Our empirical results show that the form of migration is determined by gender, age, education levels, family size, economic conditions in the region of origin, perceived wealth status and whether there are other members of household abroad.

The main contribution of circular migrants to development in Moldova is probably through increasing the aggregate demand via remittances and repatriated savings. In addition, development gains from transfers of skills and technology could probably be achieved through return migration. As shown by Piracha and Vadean (2009) for the case of Albania, many successful returnees start up own businesses and become entrepreneurs after settling back in the home country. This is likely to be the case in Moldova as well which could result in higher investment level and possibly higher productivity levels through accumulation of experience while working in a different environment abroad.

There has been limited focus on the form of migration in the existing literature, despite a significant increase in both temporary and circular migration in the last two decades. Our contribution in this field is therefore to draw more attention to the different forms of migration with the general objective of determining the determinants of who moves and for how long, i.e., for a few months, and only once or repeatedly over time. We think the results obtained could help Moldovan policymakers, and perhaps countries with similar migration patterns, as well as the receiving countries, to design policies to more effectively manage migration for the benefit of both home and host countries and the migrants. 


\section{References}

Constant, A.F., O. Nottemeyer and K.F. Zimmermann (2013). The Economics of Circular Migration, in International Handbook on the Economics of Migration, eds, A.F. Constant and K.F. Zimmermann, Edward Elgar. Forthcoming.

Constant, A. F. and K. F. Zimmermann (2012). The Dynamics of Repeat Migration: A Markov Chain Analysis, International Migration Review, 46 (2), 361-387.

Constant, A. F. and K. F. Zimmermann (2011). Circular and Repeat Migration: Counts of Exits and Years Away from the Host Country, Population Research and Policy Review, 30 (4), 495-515.

Dustmann, C. (1997). Return migration, uncertainty and precautionary savings, Journal of Development Economics, 52: 295-316

Galor, O. and Stark, O. (1990) Migrants' savings, the probability of return migration and migrants' performance, International Economic Review, 31, 463-7.

Piracha, M. and F. Vadean (2009). Return Migration and Occupational Choice: Evidence from Albania, World Development, 38(8): 1141-1155.

Piracha, M. and Y. Zhu (2012). Precautionary Savings by Natives and Immigrants in Germany, Applied Economics, 44(21): 2767-2776.

Radu, D.C. and G. Epstein (2007), "Returns to return migration and determinants of subsequent moves", EALE Conference Paper, EALE Annual Conference, 20-22 September 2007, Oslo.

Vadean, F and M. Piracha (2010). Circular Migration or Permanent Return: What Determines Different Forms of Migration, in Migration and Culture, eds. G. Epstein and I. Gang, part of Frontiers of Economics and Globalization, Emerald Press. 
Table 1. Descriptive statistics by form of migration

\begin{tabular}{|c|c|c|c|c|c|c|c|}
\hline & $\begin{array}{c}\text { Non } \\
\text { migrants }\end{array}$ & & $\begin{array}{l}\text { Permanent } \\
\text { migrants }\end{array}$ & & $\begin{array}{l}\text { Temporary } \\
\text { Migrants }\end{array}$ & & $\begin{array}{l}\text { Circular } \\
\text { migrants }\end{array}$ \\
\hline & $\begin{array}{l}\text { Mean } \\
\text { value }\end{array}$ & difference & Mean value & difference & Mean value & difference & $\begin{array}{l}\text { Mean } \\
\text { value }\end{array}$ \\
\hline \multicolumn{8}{|l|}{ Individual Characteristics } \\
\hline Age (years) & 38.53 & $6.29^{\star * \star}$ & 32.24 & $-4.68^{\star \star \star}$ & 36.92 & 0.52 & 36.40 \\
\hline Gender (dummy = 1 if a woman) & 0.53 & $-0.07^{\star \star \star}$ & 0.60 & $0.25^{\star \star \star}$ & 0.34 & -0.07 & 0.41 \\
\hline Double citizenship(MOL+RUS) (dummy=1 if yes) & 0.05 & 0.01 & 0.05 & 0.01 & 0.04 & -0.02 & 0.06 \\
\hline Education level: college (dummy=1 if yes) & 0.29 & -0.02 & 0.30 & $-0.15^{\star * *}$ & 0.45 & $0.12^{* *}$ & 0.33 \\
\hline Education level: university (dummy=1 if yes) & 0.21 & $-0.04^{\star \star \star}$ & 0.25 & $0.12^{\star \star *}$ & 0.13 & $-0.07^{*}$ & 0.20 \\
\hline Education level: post-university (dummy=1 if yes) & 0.13 & $0.04^{* * *}$ & 0.09 & $0.03^{*}$ & 0.06 & -0.02 & 0.08 \\
\hline \multicolumn{8}{|l|}{ Household Characteristics } \\
\hline No. of other $\mathrm{HH}$ members a past migrant & 0.14 & $-2.20^{\star * *}$ & 2.35 & 0.11 & 2.24 & 0.09 & 2.15 \\
\hline $\begin{array}{l}\mathrm{HH} \text { subjective economic status in } 1998 \text { (1=poor, } 5 \\
\text { rich) }\end{array}$ & 2.81 & 0.02 & 2.78 & -0.01 & 2.79 & 0.04 & 2.75 \\
\hline Proportion of children & 0.11 & $-0.01^{*}$ & 0.12 & $-0.07^{* \star *}$ & 0.19 & 0.01 & 0.17 \\
\hline Marital status: Married (dummy=1 if yes) & 0.62 & 0.00 & 0.62 & $-0.16^{\star \star \star}$ & 0.78 & 0.04 & 0.74 \\
\hline \multicolumn{8}{|l|}{ Migration type } \\
\hline Illegal migration (dummy=1 if yes) & 0.00 & $-0.11^{\star \star *}$ & 0.12 & -0.01 & 0.13 & $0.06^{* *}$ & 0.07 \\
\hline \multicolumn{8}{|l|}{ Community and Regional Characteristics } \\
\hline Economic development index (EDI) & 0.57 & $0.26^{\star \star \star}$ & 0.31 & -0.01 & 0.32 & -0.03 & 0.35 \\
\hline Social development index (SDI) & 1.39 & $0.57^{\star \star \star}$ & 0.82 & $0.23^{*}$ & 0.59 & $-0.29^{*}$ & 0.88 \\
\hline Infrastructure development index (IDI) & 0.36 & $0.17^{* * *}$ & 0.19 & 0.02 & 0.17 & -0.06 & 0.23 \\
\hline $\mathrm{N}$ & 6833 & & 2380 & & 412 & & 300 \\
\hline$\%$ & 68.85 & & 23.98 & & 4.15 & & 3.02 \\
\hline
\end{tabular}

Note: ${ }^{*} \mathrm{p}<0.05,{ }^{* *} \mathrm{p}<0.01,{ }^{* * *} \mathrm{p}<0.001$. The differences are computed between the mean values in the adjoining columns. 
Table 2. Nested Logit Regression (3 levels NL)

Variables

Coef.

$P>|z|$

3rd level : TEMPORARY MIGRATION EQUATION

Age (years)

Education level: university (dummy $=1$ if yes)

Education level: post-university (dummy $=1$ if yes)

HH subjective economic status in 1998 (1=poor, 5 rich)

Proportion of children

Economic development index (EDI)

Social development index (SDI)

Infrastructure development index (IDI)

2nd Level : RETURN MIGRATION EQUATION

Age (years)

Proportion of children

Marital status: Married (dummy $=1$ if yes)

No. of other $\mathrm{HH}$ members a past migrant

Illegal migration (dummy $=1$ if yes)

1st level : MIGRATION EQUATION

Gender (dummy $=1$ if a woman)

Double citizenship (MOL+RUS) (dummy=1 if yes)

Education level: college (dummy $=1$ if yes)

Education level: university (dummy $=1$ if yes)

Education level: post-university (dummy $=1$ if yes)

HH subjective economic status in 1998 (1=poor, 5 rich)

Economic development index (EDI)

Social development index (SDI)

Infrastructure development index (IDI)

DISSIMILARITY PARAMETERS

1st level : Migration Equation

Stay put : Base cathegory

Migrate (Std. Err.)

$0.74(0.86)$

2nd Level : Temporary Migration Equation

Stay put : Base cathegory

Stay abroad (i.e. long-term/permanent migration)

Notes: $L R$ test for IIA (tau $=1)$ : $\operatorname{chi} 2(1)=12.08$; Prob > chi2 $=0.0005$;

${ }^{*} p<0.10,{ }^{* *} p<0.05,{ }^{* * *} p<0.01$ 
Table 3. Predicted probabilities for the Three-level Nested Logit Model

\begin{tabular}{|c|c|c|c|c|c|}
\hline & & Mean & $\begin{array}{l}\text { Std. } \\
\text { Dev. }\end{array}$ & $\begin{array}{l}\text { Observed } \\
\text { Sample N }\end{array}$ & $\begin{array}{l}\text { Sample } \\
\%\end{array}$ \\
\hline Stay put & $\operatorname{Pr}(S P)$ & 0.6811 & 0.3650 & 6833 & 68.85 \\
\hline Migration & $\operatorname{Pr}(M)$ & 0.3189 & 0.3115 & 3092 & 31.15 \\
\hline Permanent migration & $\operatorname{Pr}(P M)$ & 0.2318 & 0.2890 & 2380 & 23.98 \\
\hline Temporary migration & $\operatorname{Pr}(T M)$ & 0.0479 & 0.0601 & 412 & 4.15 \\
\hline Circular migration & $\operatorname{Pr}(C M)$ & 0.0392 & 0.0440 & 300 & 3.02 \\
\hline $\begin{array}{l}\text { probability of temporary migration, } \\
\text { conditional on return }\end{array}$ & $\operatorname{Pr}(T M \mid R)$ & 0.5583 & 0.1781 & & \\
\hline $\begin{array}{l}\text { probability of circular migration, } \\
\text { conditional on return }\end{array}$ & $\operatorname{Pr}(C M \mid R)$ & 0.4417 & 0.1781 & & \\
\hline $\begin{array}{l}\text { probability of permanent migration, } \\
\text { conditional on migration }\end{array}$ & $\operatorname{Pr}(P M \mid M)$ & 0.6766 & 0.1317 & & \\
\hline $\begin{array}{l}\text { probability of return, conditional on } \\
\text { migration }\end{array}$ & $\operatorname{Pr}(R \mid M)$ & 0.3234 & 0.1317 & & \\
\hline
\end{tabular}

